\title{
Aircraft Photography in the Service of Science.
}

\section{By H. Hamshaw Thomas.}

\begin{abstract}
A IRCRAFT photography as developed during $A$ the war possesses great potentialities as an instrument of scientific research. The value of the aeroplane in geographical and geological exploration has already been emphasised in these pages, and its employment in the reconnaissance of little-known countries need not be further mentioned; but if aeroplane exploration is valuable, its worth is greatly enhanced by systematio photographic work. For, while a trained observer notices many features, it is quite impossible for him to observe and note more than the salient points seen from a swiftly flying machine, while the camera instantly records every feature in the field of view. Again, from a safe height of, say, Io,ooo $\mathrm{ft}$. only the larger elevations or depressions are visible to the human eye, but if paired photographs are taken for the purpose of stereoscopic examination with a wide base of, perhaps, 500 yards, then the whole of the ground relief becomes visible in a most striking manner. But not only do photographs provide a means of obtaining and recording information; they also show the relative positions of objects, and, if taken on an organised system, provide a topographical survey for use in map construction. In addition, I was frequently struck with the value for scientific purposes of material obtained in the course of the R.A.F. work in Egypt and Palestine, and the purpose of this article is to indicate some types of information which may be furnished.
\end{abstract}

Air photographs may serve either as useful illustrations of known scientific facts, or as a means of discovering new facts, and while they are mainly of geographical or geological interest, they may also assist the botanist, archæologist, and meteorologist.

Geography and Geology.-..As examples of the illustration of known facts, we may mention the remarkable photographs of Vesuvius taken by Group Capt. A. E. Borton, C.M.G. One of these has already been published in the Press, and it would not be easy to find a more striking demonstration of the structure of a volcanic cone. Among the photographs taken in Palestine we had many good illustrations of erosion and river development. The soft lake-beds of the Jordan valley were shown in the process of weathering out to form what the Americans term "bad-land topography." In this region marls and clays which have been baked by the hot, rainless summer are denuded at a great rate by the heavy winter rains, and give rise to a complex system of steep-sided wadis spreading back from the main drainage channels. The sides of these wadis are bare of vegetation, but their bottoms become filled with scrub when reduced to the base level of erosion.

1 See Geographical Journal, May, 1920. NO. 264 I, VOL. IO5]
The contrast between the wadi forms produced in these lacustrine or alluvial deposits and those carved out of the adjacent Cretaceous rocks is very noticeable, and we have also illustrations of the different erosion forms produced on steep or gentle slopes.

The River Jordan, which had never been very accurately surveyed before the war, has now been photographed over a considerable distance, and furnishes striking examples of some of the phenomena of river development. In its lower part it has cut down a distinct and well-marked meander-belt below the level of the surface of the lake-beds of the old valley. The river is constantly changing its course in this belt (see Fig. r), which in most places is well covered with vegeta-

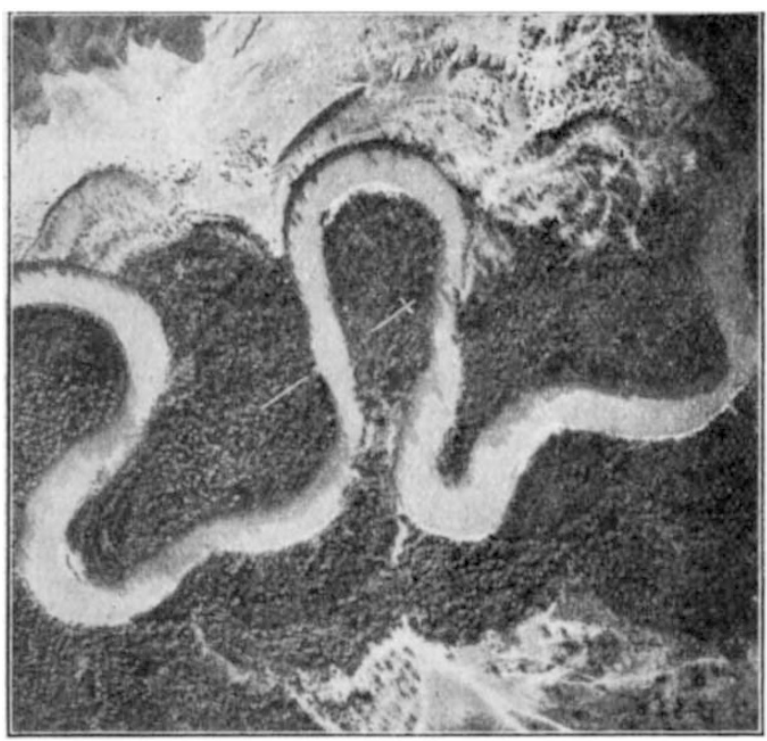

FIG. r.-Meander belt of the River Jordan north of Jericho, showing the formation of an "ox-bow" and the cusp-shaped terraces. The dark area near the stream is the belt of willow scrub.

tion, and the old courses of the stream are often plainly visible where the vegetation has not yet had time to colonise the former river-bed. We see "ox-bows" and loops of the river in all stages of development, while sometimes a heavy spring flood appears to have resulted in the stream taking an entirely new course. At the sides of the floodplain cusp-like terraces often show the stages in the cutting down of the gorge, while the presence of hard beds may produce nodes in the series of meanders.

The illustrations of such features as have been mentioned are often so striking and convincing that they would be valuable to teachers and students if they could be made available.

But by the study of photographs and the maps 
made from them we may observe other features of research interest. The story of the earth movements in the Jordan rift is not yet clear, while there has been much discussion about the climate of the region during recent and prehistoric times. In some of the photographs taken, we have good evidence of very recent faulting, and we may distinguish a fault scarp in the lake-beds (Late Tertiary). We find that the trough faulting has resulted in the incision of many of the tributary streams, and in several places in cañon formation. When we look at the drainage system from the point of view of climatic change we find evidence of a former period of abundant precipitation, during which much of the present surface sculpture of the Judæan hills was effected; but this period was a remote one, and preceded the drying up of the Jordan lake to give the present valley. Passing up to the north of Palestine, we have good evidence from a dry gorge, terraced valleys and drainage forms, that at a former period the River Jordan originated in Central Syria; but afterwards the Syrian portion of the river was captured by the Litani. This capture was largely the result of a general uplift of the country, and several of the oblique air views of the coastal plain of Palestine, especially near Mount Carmel, show very well the plain of marine denudation stretching from the present shore to the foot of the hills.

It is in the portrayal of the geographical features in the most complete and detailed fashion, so that their developmental story can be studied and deciphered, that aeroplane photography excels. If the whole of the Palestine material could be carefully studied by the physical geologist, a great deal of information would result, for the above-mentioned deductions have been made from the study of a few small sets of photographs which had been chosen at random for other purposes.

The investigator of solid geology has naturally little to learn from photographs, but in some places, where the climate is arid and the ground almost devoid of soil, the boundaries of some of the harder beds may become visible, while in other cases the bedding is clearly seen, and the underlying structure may be brought out by surface weathering. A photograph taken during the first flight ever made from Egypt to India showed an interesting locality in western Persia, where a well-marked anticline had been laid bare by surface erosion.

Botany. - The student of vegetation who may be sufficiently fortunate to obtain aerial photographs of the ground is at once in possession of the basis of an ideal vegetation map. Different types of vegetation show up very clearly, and also, of course, the transition from desert to open and closed plant associations (see Fig. 2). It is naturally necessary to go over the ground with the photographs, but after a short time the characteristic tones and appearance of different vegetation types can be readily picked out. Even among crops it is possible to distinguish barley, wheat, and NO. 264 I, VOL. IO57 maize, besides other plants, like cotton, which have a distinct habit and growth period. Practical use of these facts was made in Mesopotamia for ascertaining the acreage under wheat cultivation, and trials have been made in India with the view of carrying out crop-surveys by aeroplane photography.

I have not had the opportunity of making many observations on this subject, but it may be of interest to mention a small point observed in connection with the distribution of the willow and tamarisk scrub of the Jordan valley. This vegetation is limited by the water supply from the river, and succeeds in following the stream right down to the Dead Sea. Here, at the mouth of the Jordan, although surrounded by salt lagoons, a narrow belt of vegetation manages to survive as a fringe to the river with its rapidly flowing stream of fresh water.

Archaeology.-The utility of aerial photography to the archæologist was strikingly illustrated in

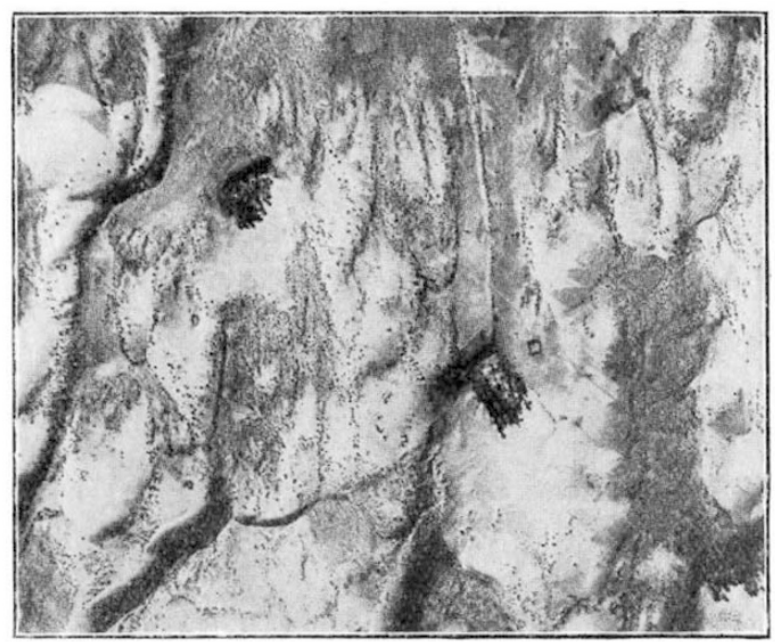

FIG. 2.-Photograph showing the distribution of vegetation in the Sinai desert. 'The partial colonisation of sand-hills by dwart scrub vegetation -the black spots-is well shown, also some small groups of date palms.

the case of the ninth-century city of Samarra, ${ }^{2}$ in Mesopotamia, where views taken from above the apparently formless heaps of earth and rubble give the outlines and plan of streets and buildings. It may be only rarely that similar cases may arise, but experience shows that if ruins or remains exist in any regular form, their arrangement will be well depicted by the aeroplane camera. We may by this means be able to locate interesting sites which have been more or less obscured by superimposed material. A feature which was brought to light in Palestine as the result of air survey was the ancient irrigation system in the south-eastern part of the Jordan valley. An extensive series of old connected channels, now filled with scrub vegetation, was seen; this must be a relic of the days when the Jordan valley was under general cultivation, 2 See I.t.-Col. G. A. Beazley, Geographical Journal, vol. liii., p. $33^{\circ}$,
rgrg. 
and very different from the desert condition which it possesses to-day. While nothing was found in Palestine of the same type as the Samarra ruins, the ancient Græco-Roman temples of Jupiter and Bacchus at Baalbek, in Central Syria,

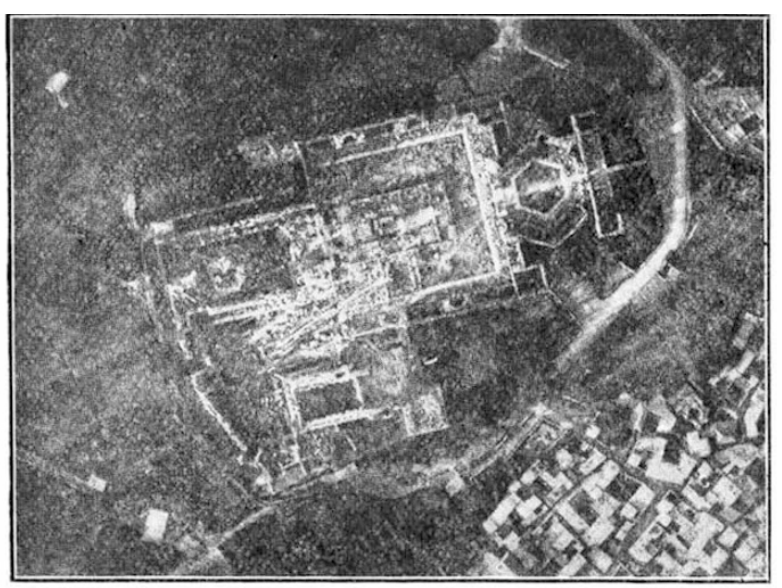

Fic. 3.-Temples of Jupiter and Bacchus at Baalbek in Central Syria, showing the ground plan and some remains of later Saracenic building.

furnished some interesting photographs. A vertical view from about $3000 \mathrm{ft}$. gives a remarkably good ground plan of the present state of these beautiful remains (see Fig. 3 ).

Meteorology.-The study of clouds by the photography from aeroplanes of their forms and features has been recently discussed by meteorologists, and need not be further mentioned.

It would be outside the scope of the present article to deal with the methods of obtaining, using, and interpreting the aerial pictures which have been referred to. It may be seldom possible for a scientific expedition to employ aeroplanes, owing to their expense; but, when it can be done, useful knowledge is bound to accrue. In other cases, however, as in Palestine, photographs may be taken for mapping or other purposes, which will also yield important scientific material to those who can make use of it; and possibly photographs taken for the purpose of training airmen may become of great value, even in this country, if certain areas are included. Sometimes the evidence furnished is clear and unmistakable, but in other cases the photographs have to be examined by a trained and experienced worker. The general public has not been very fully informed of the work of the R.A.F. photographers during the war, and to most people the air photograph is a curiosity which seems to have little value in times of peace. Though in some countries the civil importance of aerial photographic survey is realised, in England air photography is in a somewhat languishing condition. In these circumstances it is well to remember that, though the aerial camera has not been extensively employed apart from military work, it nevertheless appears to have no inconsiderable value in the domain of pure science.

\section{The Dynamics of Shell Flight.}

\section{By R. H. FOwler.}

$\mathrm{T}^{\mathrm{H}}$ $\mathrm{HE}$ object of this article is to give a short account of some features of the motion of a spinning shell through air. Our knowledge of this phenomenon has been somewhat increased by war-time researches. To determine the motion of a shell from the equations of rigid dynamics, we require to know the complete force system which represents the reaction of the air on the moving shell; but, just as in the case of an aeroplane, the components of this reaction are utterly unknown a priori. The problem that arises, therefore, is that of determining these components by observation and analysis of the actual initial motion of shells. Once they have thus been determined, they can be applied, provided the essential conditions remain similar, to the calculation of the complete motion of a shell along its trajectory.

In the simplest case of al] this procedure is classical. The air resistance to a shell, moving so that the directions of its axis and the velocity of its centre of gravity coincide, has long been determined thus as a function of the velocity, and trajectories have been computed assuming that this coincidence subsists throughout the motion. Under this assumption the problem is merely one of particle dynamics, of which the solution may be regarded as completely known. The comparison of calculations and observations shows good agreement in range and height when the shells are suitable and the total angle turned through by the tangent to the trajectory is less than, say, $50^{\circ}$. The calculated trajectory, however, is a curve lying in the vertical plane containing the original direction of projection, while the observed positions of the shells do not lie in this plane, but appreciably to the right of. it when their axial spin is right-handed. This well-known departure from the original vertical plane is called drift, and converts the trajectory into a twisted curve. It cannot be accounted for on the original assumption.

It is with these cases, in which particle dynamics fails to explain the observations-such as the drift, trajectories of large total curvature, and (as we shall see) initial motions-that we are mainly concerned here. For their study we must abandon the assumption that the direction of motion of the centre of gravity and the direction of the axis of symmetry coincide, and study the whole motion as a problem in rigid dynamics.

In order to do this we must, first of all, deter-

NO. 264 I, VOL. IO5] 